\title{
Reevaluation of Preoperative Chemoradiotherapy for Clinical T3 Lower Rectal Cancer: A Multicenter Collaborative Retrospective Clinical Study
}

\author{
MITSUMASA TAKEDA ${ }^{1}$, HIDEJIRO KAWAHARA ${ }^{1}$, MASAICHI OGAWA ${ }^{2}$, \\ KATSUHITO SUWA ${ }^{3}$, KEN ETO ${ }^{4}$ and KATSUHIKO YANAGA ${ }^{4}$ \\ ${ }^{1}$ Department of Surgery, Kashiwa Hospital, the Jikei University School of Medicine, Chiba, Japan; \\ ${ }^{2}$ Department of Surgery, Katsushika Medical Center, the Jikei University School of Medicine, Tokyo, Japan; \\ ${ }^{3}$ Department of Surgery, the Third Hospital, the Jikei University School of Medicine, Tokyo, Japan; \\ ${ }^{4}$ Department of Surgery, the Jikei University School of Medicine, Tokyo, Japan
}

\begin{abstract}
Aim: This study aimed to re-evaluate the usefulness of preoperative chemoradiotherapy for clinical T3 lower rectal cancers without lateral lymph node metastasis. Patients and Methods: Between 2010 and 2014, 132 patients with clinical T3 lower rectal cancer without lateral lymph node metastasis, 80 years of age or younger, who underwent curative resection at four Jikei University Hospitals were enrolled into this retrospective study. Of these, 22 patients received chemoradiotherapy (CRT) before surgery, 16 patients received intensive chemotherapy after surgery without preoperative CRT, and 94 patients underwent neither preoperative CRT nor intensive chemotherapy after surgery including 47 patients with postoperative oral chemotherapy for pathological diagnosis of stage III. Results: The 3-year disease-free survival (DFS) of the 22 patients who received preoperative CRT was $95.5 \%$, whereas that of the 94 patients who received neither preoperative CRT nor intensive chemotherapy was $72.0 \%(p=0.024)$. However, there was no significant difference in 5-year DFS between the two groups. No significant difference was identified in DFS between the 22 patients who received preoperative CRT and the 16 patients who received intensive chemotherapy after surgery without preoperative CRT. Conclusion: Intensive chemotherapy after surgery seems to yield a similar prognosis to preoperative CRT in patients with clinical T3 lower rectal cancer without lateral lymph node metastasis.
\end{abstract}

Correspondence to: Hidejiro Kawahara, MD, Ph.D., Department of Surgery, Kashiwa Hospital, Jikei University School of Medicine, 163-1 Kashiwashita, Kashiwashi, Chiba 277-8567, Japan. Tel: +81 471641111 Ext. 3421, Fax: +81 471633488, e-mail: kawahide@ jikei.ac.jp

Key Words: Preoperative chemoradiotherapy, lower rectal cancer, adjuvant chemotherapy, clinical T3.
Total mesorectal excision (TME) has been the worldwide gold-standard surgical procedure for rectal cancer (1). However, in Japan, TME plus lateral lymph node dissection without preoperative chemoradiotherapy (CRT) has been regarded as an optimal surgical procedure for advanced lower rectal cancer because of the reduced incidence of local recurrence or improved survival after those surgical procedures alone (2-8). In Western countries, TME plus preoperative CRT has been a standard treatment for locally advanced rectal cancer (9-16). However, the dose, duration, radiation target volumes, optimal concomitant agents, and outcomes remain controversial. This study aimed to reevaluate the usefulness of preoperative CRT for clinical T3 lower rectal cancer without lateral lymph node metastasis.

\section{Patients and Methods}

The Ethics Committee for Biomedical Research of the Jikei Institutional Review Board approved the protocol of this study [30249(9270)]. Between 2010 and 2014, 132 patients with clinical T3 lower rectal cancer without lateral lymph node metastasis, 80 years of age or younger, who underwent curative resection at four Jikei University Hospitals were enrolled in this study. Of these patients, 22 received CRT before surgery, 16 received intensive chemotherapy after surgery without preoperative CRT, and 94 underwent neither preoperative CRT nor intensive chemotherapy (IC) after surgery, including 47 patients with postoperative oral chemotherapy for pathological diagnosis of stage III (Table I). All patients $(n=132)$ underwent TME with bilateral autonomic nerve preservation without lateral pelvic lymph node dissection. Comparisons between diseasefree survival (DFS) and the received treatments were retrospectively evaluated. The medical records of all patients were reviewed and classified according to the Japanese Classification of Colorectal Carcinoma (17). According to this classification, T3 corresponds to the invasion of the subserosa. Significant differences were identified in gender, mean tumor diameter, lymphatic invasion, stage, and surgical technique between the preoperative CRT group and the nonCRT group by postoperative evaluation (Table II). 
Table I. Treatment strategies for lower rectal cancer used in the study population $(n=132)$.

\begin{tabular}{ll}
\hline Treament & $\mathrm{n}(\%)$ \\
\hline Preoperative chemoradiotherapy (CRT) & $22(17.0)$ \\
Postoperative intensive chemotherapy (IC) & $16(12.0)$ \\
Neither preoperative CRT nor postoperative IC & $94(71.0)$ \\
Oral adjuvant chemotherapy & $47(50.0)$ \\
Surgery alone & $47(50.0)$ \\
\hline
\end{tabular}

Lymph nodes detected by computed tomography (CT) with a diameter of more than $7 \mathrm{~mm}$ before CRT were regarded as metastatic lymph nodes (18).

Preoperative CRT. Radiotherapy was administered in fractions of 2 Gy per day, given 5 days per week for 4 weeks (total dose of $40 \mathrm{~Gy}$ ). UFT (Taiho Pharmaceuticals Co. Ltd, Tokyo, Japan) $\left(300 \mathrm{mg} / \mathrm{m}^{2} /\right.$ day $)$ or capecitabine (Xeloda; Hoffmann-La Roche, Basel, Switzerland) $\left(1600 \mathrm{mg} / \mathrm{m}^{2} /\right.$ day) was given orally on days 1 to 5,8 to 12,15 to 19 , and 22 to 26 as additional chemotherapy. The treatment field of radiotherapy included perirectal lymph nodes and lateral lymph nodes.

Intensive chemotherapy after surgery. The intensive chemotherapy group $(n=16)$ received oxaliplatin-based regimens [infusional 5-fluorouracil and folinic acid plus oxaliplatin (FOLFOX), S-1 (Taiho Pharmaceuticals Co. Ltd, Tokyo, Japan) plus oxaliplatin (SOX), capecitabine plus oxaliplatin (XELOX)] for 6 months after surgery.

Oral adjuvant chemotherapy after surgery. For 6 months after surgery, patients with stage III disease $(n=47)$ received oral S-1 or capecitabine, whereas patients with stage II disease $(n=47)$ received no adjuvant chemotherapy. Patients who had received preoperative CRT $(n=22)$ received no adjuvant chemotherapy.

Treatment schedule. All patients were followed for 5 years; during this period, physical examinations, routine blood analyses, and serum CEA measurements were conducted every two months after surgery. CT was performed every 6 months or when a patient's serum CEA value was higher than the normal level of $5.0 \mathrm{ng} / \mathrm{ml}$. Colonoscopy was performed every year or when a stool sample was positive for blood. Positron emission tomography (PET) or PET/CT was occasionally employed to detect occult metastasis for patients who had equivocal conventional imaging studies.

Statistical analysis. Continuous variables are expressed as the mean and range. The Wilcoxon rank-sum test was used for the comparison of continuous variables, and a chi-squared test was used for the comparison of categorical data. DFS after surgery was examined by the Kaplan-Meier method and by log-rank analysis. A $p$-value of less than 0.05 indicated significance. All data were analyzed with IBM SPSS Statistics, version 24.0 (IBM Japan, Ltd, Tokyo, Japan).

\section{Results}

Pathologic response to preoperative CRT. Preoperative CRT was successful in pathological T-downstaging 10/22 patients to smaller than T2. Pathologic complete response (pCR) was
Table II. Comparison of characteristics between preoperative chemoradiotherapy (CRT) group and non-CRT group.

\begin{tabular}{|c|c|c|c|}
\hline Characteristic & $\begin{array}{l}\text { CRT (-) } \\
(\mathrm{n}=110)\end{array}$ & $\begin{array}{c}\mathrm{CRT}(+) \\
(\mathrm{n}=22)\end{array}$ & $p$-Value \\
\hline Mean age (range), years & $65.2(36-80)$ & $63.0(50-80)$ & 0.293 \\
\hline Gender, $\mathrm{n}(\%)$ & & & 0.032 \\
\hline Male & $69(63)$ & $19(86)$ & \\
\hline Female & $41(37)$ & $3(14)$ & \\
\hline Mean tumor diameter (range), $\mathrm{mm}$ & $56.8(14-108)$ & $35.4(0-95)$ & $<0.001$ \\
\hline Pathology, n (\%) & & & 0.530 \\
\hline Well-differentiated adenocarcinoma & $28(26)$ & $8(36)$ & \\
\hline $\begin{array}{l}\text { Moderately-differentiated } \\
\text { adenocarcinoma }\end{array}$ & $73(66)$ & $13(59)$ & \\
\hline Others & $9(8)$ & $1(5)$ & \\
\hline Lymphatic invasion, $\mathrm{n}(\%)$ & & & 0.005 \\
\hline Negative & $31(28)$ & $13(59)$ & \\
\hline Positive & $79(72)$ & $9(41)$ & \\
\hline Venous invasion, $\mathrm{n}(\%)$ & & & 0.046 \\
\hline Negative & $36(33)$ & $12(55)$ & \\
\hline Positive & $74(67)$ & $10(45)$ & \\
\hline Stage, $\mathrm{n}(\%)$ & & & 0.009 \\
\hline II & $47(43)$ & $16(73)$ & \\
\hline III & $63(57)$ & $6(27)$ & \\
\hline Surgical procedure, $\mathrm{n}(\%)$ & & & 0.857 \\
\hline Low anderior resection & $65(59)$ & $14(63)$ & \\
\hline Abdominoperineal resection & $40(36)$ & $7(32)$ & \\
\hline Intersphincteric resection & $2(2)$ & $0(0)$ & \\
\hline Hartmann operation & $3(3)$ & $1(5)$ & \\
\hline Surgical technique, n (\%) & & & $<0.001$ \\
\hline Laparoscopic surgery & $46(42)$ & $19(86)$ & \\
\hline Open surgery & $64(58)$ & $3(14)$ & \\
\hline Recurrence site, n (\%) & & & 0.316 \\
\hline Lung & $20(18)$ & $2(9)$ & \\
\hline Liver & $10(9)$ & $1(5)$ & \\
\hline Brain & $2(2)$ & $0(0)$ & \\
\hline Lymph node & $2(2)$ & $0(0)$ & \\
\hline Local & $7(6)$ & $0(0)$ & \\
\hline
\end{tabular}

found in $2 / 22$ patients. Pathologic lymph node metastasis was eradicated by preoperative CRT in 4 of 10 patients.

Comparison of DFS between the preoperative CRT and nonCRT groups without intensive adjuvant chemotherapy. Significant differences were identified in gender, mean tumor diameter, lymphatic invasion, stage, and surgical technique (Table III). The 3-year DFS of 22 patients who received preoperative CRT was $95.5 \%$, whereas that of 94 patients who received neither preoperative CRT nor intensive chemotherapy after surgery was $72.0 \%(p=0.024)$ (Figure 1). However, there was no significant difference in 5-year DFS between the two groups.

Comparison of DFS between the preoperative CRT and nonCRT groups without intensive adjuvant chemotherapy in stage II rectal cancer. Significant differences were identified 


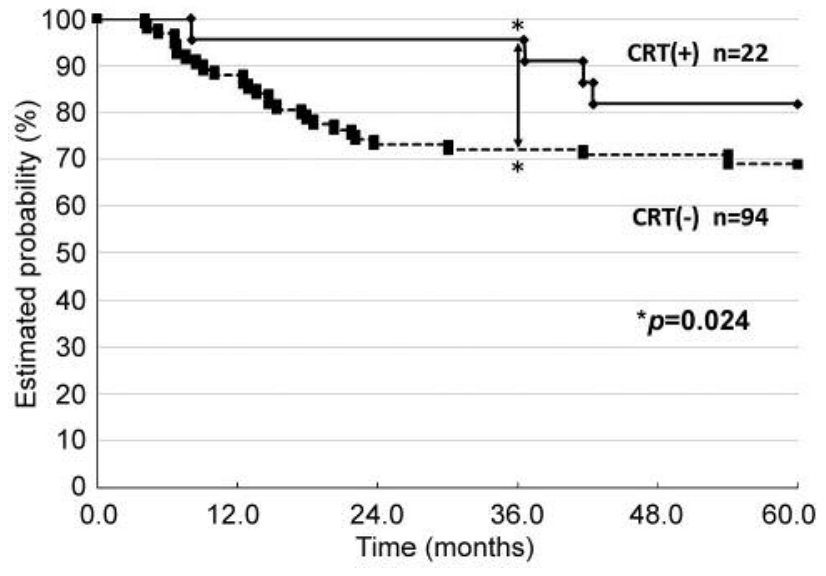

Figure 1. Comparison of disease-free survival (DFS) between the preoperative chemoradiotherapy (CRT) and non-CRT groups without intensive adjuvant chemotherapy.

Table III. Comparison of charactaristic between the preoperative chemoradiotherapy (CRT) and non-CRT groups without intensive adjuvant chemotherapy.

\begin{tabular}{|c|c|c|c|}
\hline Characteristic & $\begin{array}{c}\text { CRT }(-) \\
(\mathrm{n}=94)\end{array}$ & $\begin{array}{c}\text { CRT (+) } \\
(\mathrm{n}=22)\end{array}$ & $p$-Value \\
\hline Mean age (range), years & $66.0(36-80)$ & $63.0(50-80)$ & 0.160 \\
\hline Gender, n (\%) & & & 0.034 \\
\hline Male & $59(63)$ & $19(86)$ & \\
\hline Female & $35(37)$ & $3(14)$ & \\
\hline Mean tumor diameter (range), $\mathrm{mm}$ & $55.1(14-108)$ & $35.4(0-95)$ & 0.003 \\
\hline Pathology, n (\%) & & & 0.502 \\
\hline Well-differentiated adenocarcinoma & $23(25)$ & $8(36)$ & \\
\hline $\begin{array}{l}\text { Moderately-differentiated } \\
\text { adenocarcinoma }\end{array}$ & $64(68)$ & $13(59)$ & \\
\hline Others & $7(7)$ & $1(5)$ & \\
\hline Lymphatic invasion, n (\%) & & & 0.008 \\
\hline Negative & $27(29)$ & $13(59)$ & \\
\hline Positive & $67(71)$ & $9(41)$ & \\
\hline Venous invasion, $\mathrm{n}(\%)$ & & & 0.092 \\
\hline Negative & $33(35)$ & $12(55)$ & \\
\hline Positive & $61(65)$ & $10(45)$ & \\
\hline Stage, n (\%) & & & 0.044 \\
\hline II & $47(50)$ & $16(73)$ & \\
\hline III & $47(50)$ & $6(27)$ & \\
\hline Surgical procedure, n $(\%)$ & & & 0.893 \\
\hline Low anderior resection & $57(61)$ & $14(63)$ & \\
\hline Abdominoperineal resection & $32(34)$ & $7(32)$ & \\
\hline Intersphincteric resection & $2(2)$ & $0(0)$ & \\
\hline Hartmann operation & $3(3)$ & $1(5)$ & \\
\hline Surgical technique, n (\%) & & & $<0.001$ \\
\hline Laparoscopic surgery & $46(43)$ & $19(86)$ & \\
\hline Open surgery & $54(57)$ & $3(14)$ & \\
\hline Recurrence site, n (\%) & & & 0.328 \\
\hline Lung & $18(19)$ & $2(9)$ & \\
\hline Liver & $8(9)$ & $1(5)$ & \\
\hline Brain & $1(1)$ & $0(0)$ & \\
\hline Lymph node & $2(2)$ & $0(0)$ & \\
\hline Local & 7 (7) & $0(0)$ & \\
\hline
\end{tabular}

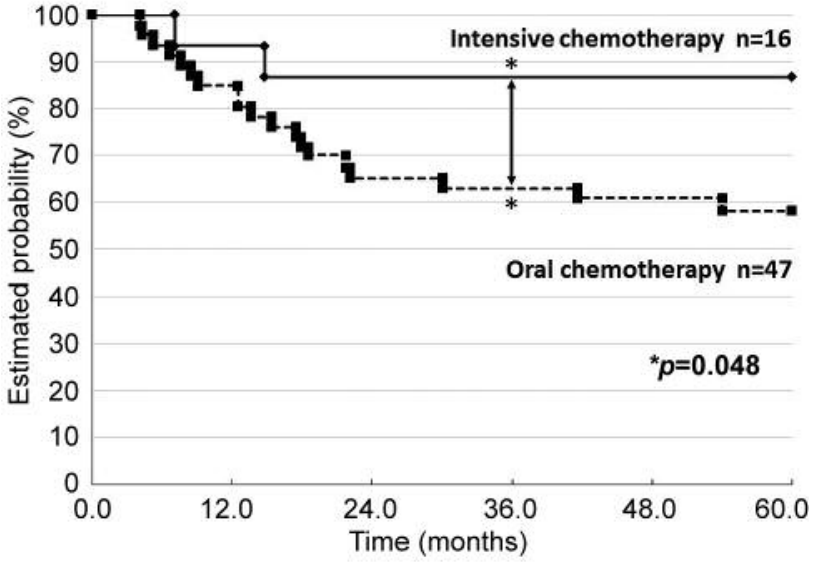

Figure 2. Comparison of disease-free survival (DFS) between the intensive and oral adjuvant chemotherapy groups.

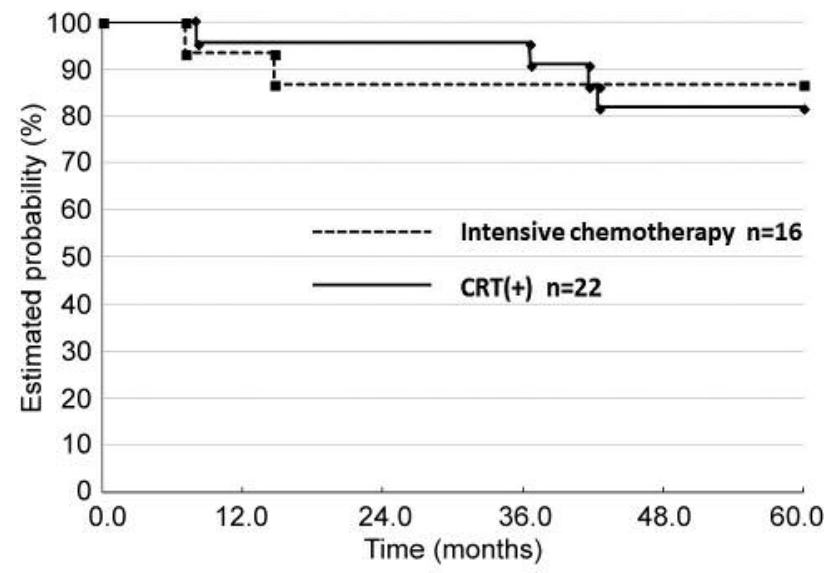

Figure 3. Comparison of disease-free survival (DFS) between the preoperative chemoradiotherapy (CRT) and non-CRT with intensive adjuvant chemotherapy groups.

in gender, mean tumor diameter, lymphatic invasion, venous invasion and surgical techniques. The 3-year DFS of 16 patients who received preoperative CRT was higher than that of 47 patients who received neither preoperative CRT nor intensive chemotherapy after surgery (100\% vs. $82.6 \%)$, however without statistical significance.

Comparison of DFS between the preoperative CRT and nonCRT groups without intensive adjuvant chemotherapy in stage III rectal cancer. Significant differences were identified in surgical techniques. The 3-year DFS of 6 patients who received preoperative CRT was $83.3 \%$, whereas that of the 47 patients who received neither preoperative CRT nor intensive chemotherapy after surgery was $63.0 \%$, which showed no significant difference. 
Table IV. Comparison of charactaristic between the intenstive and orl chemotherapy after surgery groups in stage III.

\begin{tabular}{|c|c|c|c|}
\hline Characteristic & $\begin{array}{l}\text { Intenstive } \\
\text { therapy } \\
(\mathrm{n}=16)\end{array}$ & $\begin{array}{c}\text { Oral } \\
\text { chemotherapy } \\
(\mathrm{n}=47)\end{array}$ & $p$-Value \\
\hline Mean age (range), years & $60.5(36-77)$ & $66.2(40-80)$ & 0.055 \\
\hline Gender, n (\%) & & & 0.682 \\
\hline Male & $10(63)$ & $32(68)$ & \\
\hline Female & $6(37)$ & $15(32)$ & \\
\hline Mean tumor diameter (rang), $\mathrm{mm}$ & $66.9(20-100)$ & $54.8(15-108)$ & 0.051 \\
\hline Pathology, n (\%) & & & 0.592 \\
\hline Well differentiated adenocarcinoma & $5(31)$ & $10(21)$ & \\
\hline $\begin{array}{l}\text { Moderately differentiated } \\
\text { adenocarcinoma }\end{array}$ & $9(56)$ & $33(70)$ & \\
\hline Others & $2(13)$ & $4(9)$ & \\
\hline Lymphatic invasion, n (\%) & & & 0.590 \\
\hline Negative & $4(25)$ & $7(15)$ & \\
\hline Positive & $12(75)$ & $40(85)$ & \\
\hline Venous invasion, $\mathrm{n}(\%)$ & & & 0.403 \\
\hline Negative & $3(19)$ & $16(34)$ & \\
\hline Positive & $13(81)$ & $31(66)$ & \\
\hline Surgical procedure, n (\%) & & & 0.317 \\
\hline Low anderior resection & $8(50)$ & $30(64)$ & \\
\hline Abdominoperineal resection & $8(50)$ & $14(30)$ & \\
\hline Intersphincteric resection & $0(0)$ & $1(2)$ & \\
\hline Hartmann operation & $0(0)$ & $2(4)$ & \\
\hline Surgical technique, n (\%) & & & 0.011 \\
\hline Laparoscopic surgery & $6(100)$ & $17(36)$ & \\
\hline Open surgery & $0(0)$ & $30(64)$ & \\
\hline Recurrence site, n (\%) & & & 0.003 \\
\hline Lung & $2(13)$ & $12(26)$ & \\
\hline Liver & $2(13)$ & $6(13)$ & \\
\hline Brain & $1(6)$ & $0(0)$ & \\
\hline Lymph node & $0(0)$ & $2(4)$ & \\
\hline Local & $0(0)$ & $6(13)$ & \\
\hline
\end{tabular}

Comparison of DFS between the intensive and oral adjuvant chemotherapy groups. Significant differences were identified in surgical techniques and recurrence sites (Table IV). The 3-year DFS of 16 patients who received intensive chemotherapy after surgery without preoperative CRT was $83.7 \%$, whereas that of 47 patients who received oral adjuvant chemotherapy after surgery without preoperative CRT was $63.0 \%(p=0.048)$ (Figure 2).

Comparison of DFS between the preoperative CRT and nonCRT with postoperative intensive adjuvant chemotherapy groups. Significant differences were identified in mean tumor diameter, stage, and recurrence site (Table V). The 3-year DFS of 22 patients who received preoperative CRT was higher than that of 16 patients who received intensive chemotherapy after surgery without preoperative CRT chemotherapy (95.2\% vs. $86.7 \%$ ), though without statistical significance (Figure 3).
Table V. Comparison of charactaristic between the preoperative chemoradiotherapy (CRT) and non-CRT with intensive adjuvant chemotherapy groups.

\begin{tabular}{|c|c|c|c|}
\hline Characteristic & $\begin{array}{c}\text { Intenstive } \\
\text { therapy } \\
(n=16)\end{array}$ & $\begin{array}{c}\text { CRT } \\
(+) \\
(n=22)\end{array}$ & $p$-Value \\
\hline Mean age (range), years & $60.5(36-77)$ & $63.0(50-80)$ & 0.420 \\
\hline Gender, n (\%) & & & 0.186 \\
\hline Male & $10(63)$ & $19(86)$ & \\
\hline Female & $6(37)$ & $3(14)$ & \\
\hline $\begin{array}{l}\text { Mean tumor diameter } \\
\text { (range), } \mathrm{mm}\end{array}$ & $66.9(20-100)$ & $35.4(0-95)$ & 0.001 \\
\hline Pathology, n (\%) & & & 0.662 \\
\hline $\begin{array}{l}\text { Well differentiated } \\
\text { adenocarcinoma }\end{array}$ & $5(31)$ & $8(36)$ & \\
\hline $\begin{array}{l}\text { Moderately differentiated } \\
\text { adenocarcinoma }\end{array}$ & $9(56)$ & $13(59)$ & \\
\hline Others & $2(13)$ & $1(5)$ & \\
\hline Lymphatic invasion, n (\%) & & & 0.079 \\
\hline Negative & $4(25)$ & $13(59)$ & \\
\hline Positive & $12(75)$ & $9(41)$ & \\
\hline Venous invasion, $\mathrm{n}(\%)$ & & & 0.058 \\
\hline Negative & $3(19)$ & $12(55)$ & \\
\hline Positive & $13(81)$ & $10(45)$ & \\
\hline Stage, n (\%) & & & $<0.001$ \\
\hline II & $0(0)$ & $16(73)$ & \\
\hline III & $16(100)$ & $6(27)$ & \\
\hline Surgical procedure, $\mathrm{n}(\%)$ & & & 0.306 \\
\hline Low anderior resection & $8(50)$ & $14(63)$ & \\
\hline Abdominoperineal resection & $8(50)$ & $7(32)$ & \\
\hline Intersphincteric resection & $0(0)$ & $0(0)$ & \\
\hline Hartmann operation & $0(0)$ & $1(5)$ & \\
\hline Surgical technique, n (\%) & & & 0.832 \\
\hline Laparoscopic surgery & $6(100)$ & $19(86)$ & \\
\hline Open surgery & $0(0)$ & $3(14)$ & \\
\hline Recurrence site, n (\%) & & & 0.014 \\
\hline Lung & $2(13)$ & $3(14)$ & \\
\hline Liver & $2(13)$ & $1(5)$ & \\
\hline Brain & $1(6)$ & $0(0)$ & \\
\hline Lymph node & $0(0)$ & $0(0)$ & \\
\hline Local & $0(0)$ & $0(0)$ & \\
\hline
\end{tabular}

\section{Discussion}

T4 and/or lateral lymph node metastatic tumors have a high incidence of distant metastasis, even when treated with preoperative CRT, because CRT is considered a localized treatment (19). Accordingly, only patients with lower rectal cancer diagnosed clinical T3 tumors without lateral lymph node metastasis were evaluated in this study.

The preoperative CRT group had a better 3-year DFS compared to the non-CRT group; however, no significant difference was identified in 5-year DFS between the two groups. Preoperative CRT alone has the disadvantage of higher incidence of distant failure at more than 3 years after surgery. In a recent 
multicenter randomized phase 3 trial, early T3 rectal cancer did not require CRT, and the same prognosis could be expected with a primary treatment of surgery (20). The tumor regression grade of the primary tumor is associated with oncologic outcome, and there are reports demonstrating that favorable outcomes could be expected in patients who achieved pCR or near-pCR (21-26). In other words, patients who did not achieve pCR or near-pCR after CRT cannot expect favorable outcomes. In patients treated by a contemporary intensive regimen of CRT pCR rates ranged from $20 \%$ to $30 \%(27,28)$. In this study, the pCR rate of patients with clinical T3 lower rectal cancer was only $9 \%$.

After the MOSAIC trial in which FOLFOX increased overall survival (29), 12 cycles of FOLFOX became the standard adjuvant regimen for patients with stage III colon cancer. However, it is still quite uncertain whether FOLFOX is the standard adjuvant regimen for patients with stage III rectal cancer. In the current study, the patients who received intensive chemotherapy consisting of oxaliplatin-based regimens after surgery without preoperative CRT had significantly better 3year DFS compared to patients who received oral adjuvant chemotherapy after surgery without preoperative CRT. Therefore, intensive chemotherapy consisting of oxaliplatinbased regimens appears to be the standard adjuvant regimen for patients with stage III rectal cancer.

It is uncertain whether preoperative CRT or intensive chemotherapy after surgery should be recommended for patients with clinical $\mathrm{T} 3$ rectal cancer. In this study, no significant difference was identified in DFS between the preoperative CRT group and the non-CRT with intensive chemotherapy after surgery group. From the view point of patient convenience, intensive chemotherapy after surgery may be a better choice for patients with clinical T3 rectal cancer.

In conclusion, intensive chemotherapy after surgery seems to have an outcome comparable to preoperative CRT in patients with clinical T3 lower rectal cancer without lateral lymph node metastasis; however, a large-scale prospective study is needed to clarify this issue.

\section{Conflicts of Interest}

The Authors declare that they have no conflicts of interest.

\section{Authors' Contributions}

All Authors performed operations, analyzed the data of patients regarding their clinical features, and have been involved in drafting the manuscript. KY had given final approval of the version to be published. All Authors read and approved the final manuscript.

\section{References}

1 Heald RJ, Husband EM and Ryall RD: The mesorectum in rectal cancer surgery - the clue to pelvic recurrence? Br J Surg 69(10): 613-616, 1982. PMID: 6751457.
2 Mori $\mathrm{T}$, Takahashi $\mathrm{K}$ and Yasuno $\mathrm{M}$ : Radical resection with autonomic nerve preservation and lymph node dissection techniques in lower rectal cancer surgery and its results: the impact of lateral lymph node dissection. Langenbecks Arch Surg 383(6): 409-415, 1998. PMID: 9921940.

3 Sugihara K, Moriya Y, Akasu T and Fujita S: Pelvic autonomic nerve preservation for patients with rectal carcinoma. Oncologic and functional outcome. Cancer 78(9): 1871-1880, 1996. PMID: 8909305.

4 Moriya Y, Sugihara K, Akasu T and Fujita S: Importance of extended lymphadenectomy with lateral node dissection for advanced lower rectal cancer. World J Surg 21(7): 728-732, 1997. PMID: 9276704.

5 Ueno H, Mochizuki H, Hashiguchi Y and Hase K: Prognostic determinants of patients with lateral nodal involvement by rectal cancer. Ann Surg 234(2): 190-197, 2001. PMID: 11505064.

6 Shirouzu K, Ogata Y, Araki Y, Sasatomi T, Nozoe Y, Nakagawa $\mathrm{M}$ and Matono $\mathrm{K}$ : Total mesorectal excision, lateral lymphadenectomy and autonomic nerve preservation for lower rectal cancer: significance in the long-term follow-up study. Kurume Med J 48(4): 307-319, 2001. PMID: 11830931.

7 Shimoyama M, Yamazaki T, Suda T and Hatakeyama K: Prognostic significance of lateral lymph node micrometastases in lower rectal cancer: an immunohistochemical study with CAM5.2. Dis Colon Rectum 46(3): 333-339, 2003. PMID: 12626908.

8 Numata M, Yamaguchi T, Kinugasa Y, Shiomi A, Kagawa H, Yamakawa Y, Furutani A, Manabe S and Yamaoka Y: Index of estimated benefit from lateral lymph node dissection for middle and lower rectal cancer. Anticancer Res 37(5): 2549-2555, 2017. PMID: 28476826. DOI: 10.21873/anticanres.11598

9 Sauer R, Becker H, Hohenberger W, Rödel C, Wittekind C, Fietkau R, Martus P, Tschmelitsch J, Hager E, Hess CF, Karstens JH, Liersch T, Schmidberger H and Raab R; German Rectal Cancer Study Group: Preoperative versus postoperative chemoradiotherapy for rectal cancer. New Engl J Med 351(17): 1731-1740, 2004. PMID: 15496622. DOI: 10.1056/NEJMo a040694

10 Roh MS, Colangelo LH, O'Connell MJ, Yothers G, Deutsch M, Allegra CJ, Kahlenberg MS, Baez-Diaz L, Ursiny CS, Petrelli NJ and Wolmark N: Preoperative multimodality therapy improves disease-free survival in patients with carcinoma of the rectum: NSABP R-03. J Clin Oncol 27(31): 5124-5130, 2009. PMID: 19770376. DOI: 10.1200/JCO.2009.22.0467

11 Bujko K, Nowacki MP, Nasierowska-Guttmejer A, Michalski W, Bebenek M, Pudełko M, Kryj M, Oledzki J, Szmeja J, Słuszniak J, Serkies K, Kładny J, Pamucka M and Kukołowicz P: Sphincter preservation following preoperative radiotherapy for rectal cancer: report of a randomised trial comparing short-term radiotherapy $v s$. conventionally fractionated radiochemotherapy. Radiother Oncol 72(1): 15-24, 2004. PMID: 15236870. DOI: 10.1016/j.radonc.2003.12.006

12 Gérard JP, Conroy T, Bonnetain F, Bouché O, Chapet O, ClosonDejardin MT, Untereiner M, Leduc B, Francois E, Maurel J, Seitz JF, Buecher B, Mackiewicz R, Ducreux M and Bedenne L: Preoperative radiotherapy with or without concurrent fluorouracil and leucovorin in T3-4 rectal cancers: results of FFCD 9203. J Clin Oncol 24(28): 4620-4625, 2006. PMID: 17008704. DOI: $10.1200 / J C O .2006 .06 .7629$

13 Bosset JF, Collette L, Calais G, Mineur L, Maingon P, Radosevic-Jelic L, Daban A, Bardet E, Beny A and Ollier JC; EORTC Radiotherapy Group Trial 22921: Chemotherapy with 
preoperative radiotherapy in rectal cancer. New Engl J Med 355(11): 1114-1123, 2006. PMID: 16971718. DOI: 10.1056/ NEJMoa060829

14 Yoshikawa K, Shimada M, Higashijima J, Nakao T, Nishi M, Takasu C, Kashihara H, Eto S and Bando Y: Ki-67 and Survivin as predictive factors for rectal cancer treated with preoperative chemoradiotherapy. Anticancer Res 38(3): 1735-1739, 2018. PMID: 29491110. DOI: 10.21873/anticanres.12409

15 Rades D, Vogelsang RP, Treder M, Janssen S, Schild SE, Holländer NH and Gögenur I: A Matched-pair study comparing surgery plus neoadjuvant radio-chemotherapy and surgery alone for high rectal cancers. Anticancer Res 38(12): 6877-6880, 2018. PMID: 30504404. DOI: 10.21873/anticanres.13063

16 Koizumi M, Yamada T, Shinji S, Yokoyama Y, Takahashi G, Iwai T, Takeda K, Hara K, Ohta K, Uchida E and Yoshida H: Feasibility of neoadjuvant FOLFOX therapy without radiotherapy for baseline resectable rectal cancer. In Vivo 32(4): 937-943, 2018. PMID: 29936483. DOI: 10.21873/invivo.11332

17 Japanese Society for Cancer of the Colon and Rectum: Japanese classification of colorectal carcinoma (2nd English edn.). Tokyo, Kanehara Co. Ltd, 2009.

18 Beppu N, Yanagi $\mathrm{H}$ and Tomita N: A review of preoperative chemoradiotherapy for lower rectal cancer. J Anus Rectum Colon 1(3): 65-73, 2017.

19 Erlandsson J, Holm T, Pettersson D, Berglund Å, Cedermark B, Radu C, Johansson H, Machado M, Hjern F, Hallböök O, Syk I, Glimelius B and Martling A: Optimal fractionation of preoperative radiotherapy and timing to surgery for rectal cancer (Stockholm III): a multicentre, randomised, non-blinded, phase 3, non-inferiority trial. Lancet Oncol 18: 336-346, 2017. PMID: 28190762. DOI: 10.1016/S1470-2045(17) 30086-4

20 Quah HM, Chou JF, Gonen M, Shia J, Schrag D, Saltz LB, Goodman KA, Minsky BD, Wong WD and Weiser MR: Pathologic stage is most prognostic of disease-free survival in locally advanced rectal cancer patients after preoperative chemoradiation. Cancer 113(1): 57-64, 2008. PMID: 18442099.

21 Park IJ, You YN, Agarwal A, Skibber JM, Rodriguez-Bigas MA, Eng C, Feig BW, Das P, Krishnan S, Crane CH, Hu CY and Chang GJ: Neoadjuvant treatment response as an early response indicator for patients with rectal cancer. J Clin Oncol 30(15): 1770-1776, 2012. PMID: 22493423. DOI: 10.1200/JCO.2011. 39.7901

22 Hughes R, Glynne-Jones R, Grainger J, Richman P, Makris A, Harrison M, Ashford R, Harrison RA, Livingstone JI, McDonald PJ, Meyrick Thomas J, Mitchell IC, Northover JM, Phillips R, Wallace M, Windsor A and Novell JR: Can pathological complete response in the primary tumour following preoperative pelvic chemoradiotherapy for T3-T4 rectal cancer predict for sterilization of pelvic lymph nodes, a low risk of local recurrence and the appropriateness of local excision? Int $\mathrm{J}$ Colorectal Dis 21(1): 11-17, 2006. PMID: 15864605. DOI: 10.1007/s00384-005-0749-y

23 Garcia-Aguilar J, Hernandez de Anda E, Sirivongs P, Lee SH, Madoff RD and Rothenberger DA: A pathologic complete response to preoperative chemoradiation is associated with lower local recurrence and improved survival in rectal cancer patients treated by mesorectal excision. Dis Colon Rectum 46(3): 298304, 2003. PMID: 12626903. DOI: 10.1097/01.DCR.000005 4637.75996.DF
24 Bujko K, Michalski W, Kepka L, Nowacki MP, NasierowskaGuttmejer A, Tokar P, Dymecki D, Pawlak M, Lesniak T, Richter P, Wojnar A and Chmielik E; Polish Colorectal Study Group: Association between pathologic response in metastatic lymph nodes after preoperative chemoradiotherapy and risk of distant metastases in rectal cancer: An analysis of outcomes in a randomized trial. Int J Radiat Oncol Biol Phys 67(2): 369-377, 2007. PMID: 17118570. DOI: 10.1016/j.ijrobp.2006.08.065

25 Sprenger T, Rodel F, Beissbarth T, Conradi LC, Rothe H, Homayounfar K, Wolff HA, Ghadimi BM, Yildirim M, Becker $\mathrm{H}$, Rödel C and Liersch T: Failure of downregulation of survivin following neoadjuvant radiochemotherapy in rectal cancer is associated with distant metastases and shortened survival. Clin Cancer Res 17(6): 1623-1631, 2011. PMID: 21118954. DOI: 10.1158/1078-0432.CCR-10-2592

26 Sato T, Ozawa H, Hatate K, Onosato W, Naito M, Nakamura T, Ihara A, Koizumi W, Hayakawa K, Okayasu I, Yamashita K and Watanabe M: A phase II trial of neoadjuvant preoperative chemoradiotherapy with S-1 plus irinotecan and radiation in patients with locally advanced rectal cancer: clinical feasibility and response rate. Int J Radiat Oncol Biol Phys 79(3): 677-683, 2011. PMID: 21035953.

27 Aschele C, Cionini L, Lonardi S, Pinto C, Cordio S, Rosati G, Artale S, Tagliagambe A, Ambrosini G, Rosetti P, Bonetti A, Negru ME, Tronconi MC, Luppi G, Silvano G, Corsi DC, Bochicchio AM, Chiaulon G, Gallo M and Boni L: Primary tumor response to preoperative chemoradiation with or without oxaliplatin in locally advanced rectal cancer: Pathologic results of the STAR-01 randomized phase III trial. J Clin Oncol 29(20): 2773-2780, 2011. PMID: 21606427. DOI: 10.1200/JCO. 2010.34.4911

28 André T, Boni C, Navarro M, Tabernero J, Hickish T, Topham C, Bonetti A, Clingan P, Bridgewater J, Rivera F and de Gramont A: Improved overall survival with oxaliplatin, fluorouracil, and leucovorin as adjuvant treatment in stage II or III colon cancer in the MOSAIC trial. J Clin Oncol 27(19): 3109-3116, 2009. PMID: 19451431 DOI: $10.1200 / J C O .2008 .20 .6771$

29 Akiyoshi T, Matsueda K, Hiratsuka M, Unno T, Nagata J, Nagasaki T, Konishi T, Fujimoto Y, Nagayama S, Fukunaga Y and Ueno M: Indications for lateral pelvic lymph node dissection based on magnetic resonance imaging before and after preoperative chemoradiotherapy in patients with advanced low $\square$ rectal cancer. Ann Surg Oncol 22(Suppl 3): S614-S620, 2015. PMID: 25896145. DOI: 10.1245/s10434-015-4565-5 